\title{
Time trends in preventive drug treatment after myocardial infarction in older patients
}

Wouter de Ruijter, Margot WM de Waal, Jacobijn Gussekloo, Willem JJ Assendelft and Jeanet W Blom

\begin{abstract}
Secondary preventive drug treatment in patients aged $\geq 60$ years with a history of myocardial infarction was investigated for age-dependent differences in time trends. Sixteen general practices in the Netherlands participated. Preventive treatment with at least three of four drugs (antithrombotics, statins, beta-blockers, and/or angiotensin-converting enzyme inhibitors) increased significantly over time in all three age strata of older patients. Although the greatest relative increase (2.2 times greater) took place in patients aged $\geq 80$ years, these patients consistently had most room for improvement.

\section{Keywords}

age factors; drug therapy; general practice; myocardial infarction; secondary prevention.
\end{abstract}

\section{INTRODUCTION}

The incidence of myocardial infarction (MI) increases with age, and the prognosis worsens. ${ }^{1}$ Secondary prevention following $\mathrm{Ml}$ involves treatment with a combination of four preventive drugs which is believed to result in a cumulative risk reduction of about $75 \%$, regardless of age. ${ }^{2}$ The current study investigated time trends (2000-2007) in preventive drug treatment in community-dwelling patients aged $\geq 60$ years with a history of MI.

\section{METHOD}

At three points in time, in the years 2000, 2004, and 2007 all registered and living patients aged $\geq 60$ years with the diagnosis 'myocardial infarction' confirmed in their medical records (code $\mathrm{K} 75$, International Classification of Primary Care) were selected from the Registration Network of General Practices associated with Leiden University (RNUH-LEO), a database of electronic medical records of all patients listed in 16 regular general practices in the western part of the Netherlands. Data extractions were cross-sectional, and patients could reappear in consecutive samples. Complete records of drug prescriptions during the year preceding the above-mentioned three time points were extracted. Availability (in days) of antithrombotics (Anatomical Therapeutic Chemical codes $\mathrm{B} 1 \mathrm{AA}^{*}$ or $\left.\mathrm{B} 01 \mathrm{AC}^{*}\right)$, statins $\left(\mathrm{C} 10 \mathrm{~A} \mathrm{~A}^{*}\right)$, betablockers $\left(\mathrm{CO}^{*}\right)$, and angiotensin-converting enzyme (ACE) inhibitors $\left(\mathrm{CO9A}^{*}\right.$ or $\left.\mathrm{CO9B}^{*}\right)$ in the preceding year was calculated by dividing the total number of prescribed pills in a year by the prescribed daily dose. If this resulted in 183 or more days per year of pill availability (corresponding to more than $50 \%$ of the year), preventive treatment with this specific drug was arbitrarily considered sufficient. If the time since last MI was less than 1 year, the required number of days of pill availability was proportionally adjusted. Per drug category, and within strata by age (60-69, $70-79$, and $\geq 80$ years), proportions of patients with sufficient treatment were assessed. Finally, per age stratum, overall sufficient preventive treatment was measured, defined as sufficient treatment with at least three of four categories of drugs. 


\section{How this fits in}

Secondary preventive drug treatment following myocardial infarction (MI) in older patients has been reported as incomplete, which is in contravention of current guidelines. Although preventive drug treatment in post-MI patients aged $\geq 60$ years and over showed a steep increase in recent years, particularly in the oldest old ( $\geq 80$ years), it is advised that GPs periodically review the preventive drug regimens of their (older) post-Ml patients to ensure optimisation with current guidelines.

Table 1. Characteristics and overall preventive drug treatment in patients aged $\geq 60$ years with a history of myocardial infarction (total $\boldsymbol{n}=\mathbf{8 0 0}$ ), at three time points

\begin{tabular}{|c|c|c|c|}
\hline & $2000, n=232$ & $2004, n=266$ & $2007, n=302$ \\
\hline Proportion of males & 70 (64 to 76$)$ & 74 (69 to 79 ) & 72 (67 to 77 ) \\
\hline \multicolumn{4}{|l|}{ Age group, years } \\
\hline $60-69$ & 43 (36 to 49 ) & 44 (39 to 50 ) & 40 (35 to 46$)$ \\
\hline $70-79$ & 34 (29 to 41$)$ & 34 (29 to 40 ) & 36 (31 to 41 ) \\
\hline$\geq 80$ & 23 (18 to 29$)$ & 21 (17 to 27 ) & 24 (19 to 29 ) \\
\hline \multicolumn{4}{|c|}{ Preventive drug treatment ${ }^{\mathrm{b}}$} \\
\hline Antithrombotics & 81 (76 to 86$)$ & 85 (81 to 89 ) & 88 (84 to 91$)$ \\
\hline Statins & 44 (38 to 50$)$ & 67 (61 to 72$)$ & 71 (65 to 76$)$ \\
\hline Beta-blockers & 40 (34 to 46$)$ & 52 (46 to 58 ) & 58 (52 to 63 ) \\
\hline ACE-inhibitors & 30 (25 to 36$)$ & 36 (31 to 42 ) & 47 (41 to 52 ) \\
\hline 3 to 4 drugs & 33 (27 to 39 ) & 52 (46 to 58 ) & 60 (54 to 65 ) \\
\hline
\end{tabular}

a Data presented as percentages $(95 \% \mathrm{Cls})$. ${ }^{\mathrm{D} P i l l s}$ available for more than $50 \%$ of days in preceding year. $A C E$ = angiotensin-converting enzyme.

Table 2. Preventive drug treatment ${ }^{a}$ in patients aged $\geq 60$ years with a history of myocardial infarction, depending on age group, at three time points. ${ }^{b}$

\begin{tabular}{|c|c|c|c|}
\hline & $\begin{array}{c}2000, \\
\text { total } n=232\end{array}$ & $\begin{array}{c}2004, \\
\text { total } n=266\end{array}$ & $\begin{array}{c}2007 \\
\text { total } n=302\end{array}$ \\
\hline Age $60-69$ years & $n=99$ & $n=118$ & $n=122$ \\
\hline 3-4 drugs & 38 (29 to 48 ) & 59 (50 to 68 ) & 70 (62 to 78$)$ \\
\hline \multicolumn{4}{|l|}{ Type of drug } \\
\hline Antithrombotics & 78 (69 to 85$)$ & 83 (75 to 89 ) & 89 (83 to 94 ) \\
\hline Statins & 56 (46 to 65 ) & 78 (70 to 84$)$ & 77 (69 to 84$)$ \\
\hline Beta-blockers & 42 (33 to 52 ) & 53 (44 to 62 ) & 63 (54 to 71$)$ \\
\hline ACE inhibitors & 28 (20 to 38$)$ & 38 (30 to 47 ) & 57 (48 to 65 ) \\
\hline Age $70-79$ years & $n=80$ & $n=91$ & $n=108$ \\
\hline 3-4 drugs & 34 (24 to 45$)$ & 49 (39 to 60$)$ & 55 (45 to 64 ) \\
\hline \multicolumn{4}{|l|}{ Type of drug } \\
\hline Antithrombotics & 85 (76 to 91$)$ & 86 (77 to 91$)$ & 86 (78 to 91$)$ \\
\hline Statins & 46 (36 to 57 ) & 67 (57 to 76 ) & 73 (64 to 81$)$ \\
\hline Beta-blockers & 35 (25 to 46$)$ & 51 (40 to 61 ) & 56 (47 to 65 ) \\
\hline ACE inhibitors & 35 (25 to 46$)$ & 30 (21 to 40$)$ & 39 (30 to 48$)$ \\
\hline Age $\geq 80$ years & $n=53$ & $n=57$ & $n=72$ \\
\hline $3-4$ drugs & 23 (13 to 36$)$ & 40 (29 to 53 ) & 50 (39 to 61) \\
\hline \multicolumn{4}{|l|}{ Type of drug } \\
\hline Antithrombotics & 83 (71 to 91$)$ & 89 (79 to 95$)$ & 89 (80 to 94$)$ \\
\hline Statins & 19 (11 to 31$)$ & 44 (32 to 57 ) & 57 (45 to 68 ) \\
\hline Beta-blockers & 42 (29 to 55$)$ & 51 (38 to 63) & 50 (39 to 61) \\
\hline ACE inhibitors & 28 (18 to 42$)$ & 42 (30 to 55$)$ & 42 (31 to 53 ) \\
\hline
\end{tabular}

${ }^{a}$ Pills available for more than $50 \%$ of days in preceding year. ${ }^{b}$ Data presented as percentages $(95 \% \mathrm{Cls})$. ACE = angiotensin-converting enzyme.

\section{RESULTS}

The population under observation (all patients aged $\geq 60$ years) in 2000 was 3655 (13.1\% of all registered patients), increasing to 4419 (14.9\% of all registered patients) in 2004, and 5913 (16.7\% of all registered patients) in 2007. The proportions of post-MI patients were $6.3 \%$ (232/3655), 6.0\% (266/4419), and 5.1\% (302/5913) respectively.

Characteristics of all post-Ml patients at the three time points, as well as overall preventive drug treatment (at least three of four drugs) are summarised in Table 1. At all time points, more than $80 \%$ of all post-Ml patients were treated with antithrombotics, while treatment with beta-blockers and ACE inhibitors showed a moderate increase over time. The most obvious increase in treatment over time was observed with statins. Overall, sufficient preventive treatment doubled over time, from $33 \%$ of all post-Ml patients in 2000 to $60 \%$ of patients in 2007 .

Table 2 presents preventive drug treatment in strata by age at the three time points. In all age groups, overall sufficient preventive treatment increased over time. The relative increase between 2000 and 2007 was highest in patients aged $\geq 80$ years (2.2 times greater), although by 2007 still only half of these patients received sufficient preventive drug treatment. Regarding specific drugs, treatment with antithrombotics was high in all age groups at all time points, whereas preventive treatment with all other drugs, mainly statins, increased over time. In the age group 60-69 years, treatment with ACE inhibitors doubled between 2000 and 2007.

\section{DISCUSSION}

\section{Summary of main findings}

This study shows that sufficient preventive drug treatment in patients aged $\geq 60$ years with a history of MI doubled over a recent 7-year period. In all age groups, considerable improvements were observed, with the greatest relative increase in patients aged $\geq 80$ years. However, absolute differences in treatment between age groups were equally remarkable: in 2007, more than two-thirds of all patients aged 60-69 years were on sufficient preventive drug treatment, as opposed to half of the patients aged $\geq 80$ years. The oldest old patients therefore still have the most room for improvement.

The observed increase of preventive drug treatment over time can partly be explained by changes in medical guidelines, recommending an increasing number of preventive drugs over time, as evidence of their effectiveness became available. Furthermore, guidelines have abandoned upper age limits. ${ }^{3}$ Together, these changes may also explain the continual lagging behind of preventive drug treatment in the oldest old. 


\section{Strengths and limitations of the study}

It could be seen as a limitation that it was not possible to adjust the results for possible confounders and comorbidities. However, as this was consistently so over time, it is unlikely that the nature of the observed time trends would have been much different.

\section{Comparison with existing literature}

These data are roughly in line with existing relevant literature. ${ }^{4-6}$ Surprisingly, a study from Aberdeen, UK, yielded a seemingly opposite result, with the oldest patients being more likely to receive 'at least one out of four secondary preventive drugs'. ${ }^{6}$ As this latter definition for sufficient secondary prevention differs substantially from the one used in the present study, the findings of these two studies cannot straightforwardly be compared.

\section{Implications for clinical practice}

The study findings suggest that, although over the last 7 years the oldest old post-MI patients are catching up with their younger counterparts, they still have most room for improvement. On referring these patients back to primary care, the medical specialist should therefore recommend that GPs periodically review patients' preventive drug regimens to ensure adherence with the latest guidelines.

\section{Competing interests}

The authors have stated that there are none

\section{Acknowledgements}

We thank Professor Rudi GJ Westendorp, Department of Gerontology and Geriatrics, Leiden University Medical Centre, for critically reviewing the manuscript.

\section{Discuss this article}

Contribute and read comments about this article on the Discussion Forum: http://www.rcgp.org.uk/bjgp-discuss

\section{REFERENCES}

1. Rich MW. Epidemiology, clinical features, and prognosis of acute myocardial infarction in the elderly. Am J Geriatr Cardiol 2006; 15(1): $7-11$

2. Yusuf $\mathrm{S}$. Two decades of progress in preventing vascular disease. Lancet 2002; 360(9326): $2-3$.

3. Smith SC, Allen J, Blair SN, et al. AHA/ACC guidelines for secondary prevention for patients with coronary and other atherosclerotic vascular disease: 2006 update - endorsed by the National Heart, Lung, and Blood Institute. Circulation 2006; 113(19): 2363-2372.

4. DeWilde S, Carey IM, Richards N, et al. Trends in secondary prevention of ischaemic heart disease in the UK 1994 2005: use of individual and combination treatment. Heart 2008; 94(1): 83-88.

5. Ramsay SE, Whincup PH, Lawlor DA, et al. Secondary prevention of coronary heart disease in older patients after the national service framework: population based study. BMJ 2006; 332(7534): 144-145.

6. Simpson CR, Hannaford PC, Williams D. Evidence for inequalities in the management of coronary heart disease in Scotland. Heart 2005; 91(5): 630-634. 